NASA/TM-2004-213191

\title{
Radiation in Space and Its Control of Equilibrium Temperatures in the Solar System
}

\author{
Albert J. Juhasz \\ Glenn Research Center, Cleveland, Ohio
}


Since its founding, NASA has been dedicated to the advancement of aeronautics and space science. The NASA Scientific and Technical Information (STI) Program Office plays a key part in helping NASA maintain this important role.

The NASA STI Program Office is operated by Langley Research Center, the Lead Center for NASA's scientific and technical information. The NASA STI Program Office provides access to the NASA STI Database, the largest collection of aeronautical and space science STI in the world. The Program Office is also NASA's institutional mechanism for disseminating the results of its research and development activities. These results are published by NASA in the NASA STI Report Series, which includes the following report types:

- $\quad$ TECHNICAL PUBLICATION. Reports of completed research or a major significant phase of research that present the results of NASA programs and include extensive data or theoretical analysis. Includes compilations of significant scientific and technical data and information deemed to be of continuing reference value. NASA's counterpart of peerreviewed formal professional papers but has less stringent limitations on manuscript length and extent of graphic presentations.

- TECHNICAL MEMORANDUM. Scientific and technical findings that are preliminary or of specialized interest, e.g., quick release reports, working papers, and bibliographies that contain minimal annotation. Does not contain extensive analysis.

- CONTRACTOR REPORT. Scientific and technical findings by NASA-sponsored contractors and grantees.
- CONFERENCE PUBLICATION. Collected papers from scientific and technical conferences, symposia, seminars, or other meetings sponsored or cosponsored by NASA.

- SPECIAL PUBLICATION. Scientific, technical, or historical information from NASA programs, projects, and missions, often concerned with subjects having substantial public interest.

- TECHNICAL TRANSLATION. Englishlanguage translations of foreign scientific and technical material pertinent to NASA's mission.

Specialized services that complement the STI Program Office's diverse offerings include creating custom thesauri, building customized databases, organizing and publishing research results ... even providing videos.

For more information about the NASA STI Program Office, see the following:

- Access the NASA STI Program Home Page at http://www.sti.nasa.gov

- E-mail your question via the Internet to help@sti.nasa.gov

- Fax your question to the NASA Access Help Desk at 301-621-0134

- Telephone the NASA Access Help Desk at 301-621-0390

- Write to:

NASA Access Help Desk

NASA Center for AeroSpace Information 7121 Standard Drive

Hanover, MD 21076 
NASA/TM-2004-213191

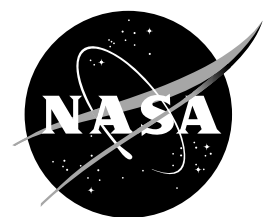

\title{
Radiation in Space and Its Control of Equilibrium Temperatures in the Solar System
}

\author{
Albert J. Juhasz \\ Glenn Research Center, Cleveland, Ohio
}

Prepared for the

34th International Conference on Environmental Systems (ICES)

cosponsored by the SAE, AIAA, AIChE, ASME, and the International ICES Committee Colorado Springs, Colorado, July 19-22, 2004

National Aeronautics and

Space Administration

Glenn Research Center 
This report is a formal draft or working paper, intended to solicit comments and ideas from a technical peer group.

This report is a preprint of a paper intended for presentation at a conference. Because of changes that may be made before formal publication, this preprint is made available with the understanding that it will not be cited or reproduced without the permission of the author.

Available from

NASA Center for Aerospace Information 7121 Standard Drive

Hanover, MD 21076
National Technical Information Service 5285 Port Royal Road Springfield, VA 22100 


\title{
Radiation in Space and Its Control of Equilibrium Temperatures in the Solar System
}

\author{
Albert J. Juhasz \\ NASA Glenn Research Center, Cleveland, Ohio 44135
}

\begin{abstract}
The problem of determining equilibrium temperatures for reradiating surfaces in space vacuum was analyzed and the resulting mathematical relationships were incorporated in a code to determine space sink temperatures in the solar system. A brief treatment of planetary atmospheres is also included. Temperature values obtained with the code are in good agreement with available spacecraft telemetry and meteorological measurements for Venus and Earth. The code has been used in the design of space power system radiators for future interplanetary missions.
\end{abstract}

\section{INTRODUCTION}

In the design of space power system radiators for missions within the solar system one of the main input variables is the space environmental temperature, also referred to as the equilibrium space sink temperature. The purpose of this report is to derive a procedure for determining space sink temperatures in the solar system.

The environmental conditions within the solar system are controlled by the energy and particle outflow from our central type G star, popularly referred to as the "Sun". A total of nine satellites, called planets, orbit the Sun, which is located at a focal point of each of the planetary elliptical orbits of varying eccentricity, ranging from 0.0068 for the almost circular orbit of Venus to 0.25 for the highly elliptic orbit of Pluto. The eccentricity for the Earth's orbit is 0.0167 , which implies that at closest approach to the sun, or perihelion, the sun-to-Earth "semi-minor" radial distance is 147.5 million $\mathrm{km}$, while at aphelion the semi-major radial distance is approximately 152.5 million $\mathrm{km}$. The distance outward from the sun to "Earth", its third orbiting planet, is thus an average of $149.6 \times 10^{6} \mathrm{~km}$ which has been defined as a unit for astronomical measurements being equivalent to $1 \mathrm{AU}$ (astronomical unit).

The furthest planet orbiting the sun is Pluto at an average distance of $40 \mathrm{AU}$. However, the boundary of the Solar system extends to the Heliopause, located between 100 and $200 \mathrm{AU}$. To gain a deeper insight into nature and magnitude of the sun's energy outflow, a brief

overview of the nuclear fusion processes taking place in the sun's core are in order.

HELIUM FUSION IN THE SUN'S CORE VIA THE PROTON-PROTON CHAIN REACTION

The most important process in the Sun is the transformation of hydrogen to helium, which is the source of the Sun's energy output. In the core of the Sun the density and temperature $\left(>8 \times 10^{6} \mathrm{~K}\right)$ are sufficiently high that frequent and violent collision between electrons, protons and other nucleons take place. Many of the proton collisions occur with such great collision energy, that in spite of electrical repulsion the colliding protons approach to with their own diameter, namely one Fermi, equivalent to $10^{-15} \mathrm{~m}$. At such distances the attraction of the nuclear force can act to fuse the protons together. At solar core temperatures the Sun's energy output is believed to be due principally to a sequence of fusion reactions, referred to as the proton-proton chain reactions, or proton-proton cycle, frequently abbreviated as the $p-p$ cycle. The individual steps in the cycle are shown in nuclear reaction equations (1) to (4) followed by a brief discussion of each reaction step. The nuclear reactions and the energy release rates from each are

$$
\begin{aligned}
& { }_{1}^{1} \mathrm{H}+{ }_{1}^{1} \mathrm{H} \rightarrow{ }^{2}{ }_{1} \mathrm{H}+\mathrm{e}^{+}+\mathrm{v} \quad(0.42 \mathrm{MeV}) \\
& \mathrm{e}^{+}+\mathrm{e}^{-} \rightarrow \mathrm{V} \text { (radiation) } \quad(1.02 \mathrm{MeV}) \\
& { }_{1}^{1} \mathrm{H}+{ }_{1}^{2} \mathrm{H} \rightarrow{ }^{3}{ }_{2} \mathrm{He}+\mathrm{Y} \quad(5.49 \mathrm{MeV}) \\
& { }_{2}^{3} \mathrm{He}+{ }_{2}^{3} \mathrm{He} \rightarrow{ }^{4}{ }_{2} \mathrm{He}+{ }_{1}^{1} \mathrm{H}+{ }_{1}^{1} \mathrm{H} \quad(12.86 \mathrm{MeV})
\end{aligned}
$$

Equation (1) shows that two protons combine to form a deuterium nucleus (heavy hydrogen containing a neutron and a proton) along with a positron $\left(\mathrm{e}^{+}\right)$and a near massless "neutrino" which, contrary to photons, escapes at near luminal velocity into space in about two seconds, unimpeded by reflective collisions in its path from the Sun's core to the surface. In contrast, photons require many thousands of and up to a million years to reach the surface and begin their voyage through space. As shown in Eq. (2), the positron quickly collides with an electron and the two antiparticles are annihilated, their mass being converted into energy in the form of gamma photons. The energy released can be computed by 
substituting the masses for the electron and positron into Einstein's equation

$$
E=m c^{2}
$$

or $E=\left(9.1 \times 10^{-31} \mathrm{~kg}+9.1 \times 10^{-31} \mathrm{~kg}\right) \times\left(3 \times 10^{8} \mathrm{~m} / \mathrm{sec}\right)^{2}$

Solving Eq. (5) shows $E=1.638 \times 10^{-13}$ Joules, or $1.02 \mathrm{MeV}$, as shown above.

In the next step of the $p-p$ cycle (Eq. 3) a hydrogen nucleon (proton) fuses with a previously formed deuterium nucleus to form a nucleus of the helium 3 isotope releasing additional gamma ray photon energy of $5.49 \mathrm{MeV}$. In the final reaction of the sequence, depicted by Eq. (4), two ${ }_{2}^{3}$ He isotopes fuse to form the stable helium 4 isotope along with two protons (hydrogen nucleons) and an energy release of $12.86 \mathrm{MeV}$.

Since, as shown in Eq. (4), two atoms of ${ }_{2}^{3} \mathrm{He}$ are required to produce the final ${ }_{2}^{4} \mathrm{He}$ nucleus, and with the reaction steps 1 to 4 documenting the production of each ${ }_{2}{ }_{2} \mathrm{He}$ isotope nucleus, it is obvious that two reactions each for steps Eqs. (1) to (3) are required to enable the final reaction step shown in Eq. (4). Hence to arrive at the total energy release for the complete cycle, we have

$$
E_{t}=2(0.42 \mathrm{MeV}+1.02 \mathrm{MeV}+5.49 \mathrm{MeV})+12.86 \mathrm{MeV}
$$

Performing the addition yields $\mathrm{E}_{\mathrm{t}}=26.7 \mathrm{MeV}$.

The net effect of the $p-p$ cycle is that four protons combine to form one ${ }_{2}^{4}$ He nucleus plus two positrons, two neutrinos, and two gamma rays, as can be illustrated by the summation of reaction steps Eqs. (1) to (4)

$$
4{ }_{1}^{1} \mathrm{H} \rightarrow{ }_{2}^{4} \mathrm{He}+2 \mathrm{e}^{+}+2 \mathrm{v}+2 \mathrm{y}
$$

The first reaction, the formation of deuterium from two protons, has a very low probability and thus places a limit on the rate at which the Sun produces energy. Nevertheless the Sun produces energy at a phenomenal rate as becomes evident by computing (as per reference 1, chapter 13) the mass loss inherent in Eq. (3).

Using atomic mass units $(\mathrm{u})$, each proton has a mass of $1.0078265 \mathrm{u}$, while the helium nucleus ( $\alpha$ particle) mass is $4.002603 \mathrm{u}$. Substituting in Eq. (3) we have

$$
\begin{aligned}
4 \times 1.0078265 u=4.002603 u+ \\
\left(2 e^{+}+2 v+2 y+12.86 \mathrm{MeV}\right)
\end{aligned}
$$

where the term in parentheses represents the total energy release rate, $E$, which can be computed from Eq. (4) as shown in Eq. (6)

$$
\begin{array}{r}
E=(4.0313008-4.002603) \mathrm{u} \times 1.66 \times 10^{-27} \mathrm{~kg} / \mathrm{u} \times \\
\left(3 \times 10^{8} \mathrm{~m} / \mathrm{sec}\right)^{2}
\end{array}
$$

or $E=26.76 \mathrm{MeV}$ per $p-p$ cycle.

Note that the result obtained in Eq. (9) agrees with the value obtained by adding the energy output values from each of the sequences in the $p-p$ cycle, as shown in Eq. (6).

Considering the Sun's total energy output, which can be computed from precision radiometer measurements, it has been determined that the number of cycles taking place in the solar core per second is $\sim 9 \times 10^{37}$. Hence the total energy output is

$$
E_{T}=26.76 \mathrm{MeV} \times 1.602 \times 10^{-13} \mathrm{~J} / \mathrm{MeV} \times 9 \times 10^{37} / \mathrm{sec}(10)
$$

$=3.86 \times 10^{26} \mathrm{~J} / \mathrm{sec}=3.86 \times 10^{26}$ Watts, which is referred to as the "Solar Luminosity", L.

Multiplying the mass loss per cycle by $9 \times 10^{37} / \mathrm{sec}$, one obtains

$$
\begin{aligned}
(4.0313008-4.002603) \mathrm{u} \times & 1.66 \times 10^{-27} \mathrm{~kg} / \mathrm{u} \times \\
& 9 \times 10^{37} / \mathrm{sec}=4.3 \times 10^{9} \mathrm{~kg} / \mathrm{sec}
\end{aligned}
$$

In other words, $\sim 4.3$ million tons of solar mass are being converted into energy every second. While this prodigious mass loss might appear excessively large, it is but a miniscule fraction of the Sun's total mass of $\sim 1.98 \times 10^{30} \mathrm{~kg}$. During its approximately 10 billion year lifetime less than 0.05 percent of the original solar mass will have been lost in this energy conversion process. The end of the our home star's role as the energy source for the Solar System will be due to its 100 fold swelling to a "red giant" stage, a shedding of its outer layers in a "nova" explosion, followed by contraction through a super dense "white" dwarf phase to an eventual dense Black dwarf status, in a process phases that will take additional billions of years.

\section{ENVIRONMENTAL TEMPERATURES IN THE SOLAR SYSTEM}

Having briefly examined the processes governing the energy generation of the Sun, let us focus on how this energy outflow in $4 \pi$ steradian directions controls the thermal environment in the Solar System space, both for spacecraft, as well as planetary bodies. But first a short review of thermal radiation heat transfer is in order.

As first deduced empirically in 1879 by Stefan from detailed experimental data obtained earlier by Tyndall, the energy per unit area radiated by a black body is proportional to the fourth power of its absolute temperature, or

$$
E_{b}=\sigma T^{4}
$$

where in $\mathrm{SI}$ units $T$ is the absolute temperature in $\mathrm{K}$ (kelvins) and $\sigma$ is the Stefan-Boltzmann Constant = $5.67 \times 10^{-8} \mathrm{Watt} / \mathrm{m}^{2} \mathrm{~K}^{4}$. 
As shown in thermal radiation texts, Radiative Heat Transfer, $Q$, between two bodies at absolute temperatures $T_{1}$ and $T_{2}$ can be expressed as

Thus

$$
Q=\sigma \varepsilon F_{v} A_{s}\left(T_{1}^{4}-T_{2}^{4}\right)
$$

where

$Q$ is the heat flow in Watts (Joules/sec)

$\varepsilon \quad$ is the emissivity of the radiating surface ( $\varepsilon=1$ for "black" body; $\varepsilon<1$ for "gray" body)

$A_{s}$ is the radiating surface area

$F_{v}$ is the surface area view factor between the radiating bodies

Objects in the vacuum of space at arbitrary temperatures, $T_{R}$, lose heat by radiating to a space environment, or space sink, temperature, $T_{s}$, which is very near to absolute zero $(\sim 1$ to $3 \mathrm{~K})$ in interstellar space. However, in the neighborhood of the inner planets of the Solar System, $T_{s}$, actually is a function of thermal properties of the radiating surfaces of the body, as well as its distance from and orientation relative to radiative flux from a heat source, such as the Sun. Another important factor is the view factor to the "black" space background.

Taking all of the above factors into account will result in low Earth orbit (LEO) equilibrium space sink temperatures ranging between 200 to $300 \mathrm{~K}$. Hence to correctly size the areas for space satellite radiators which operate at temperatures between 300 to $400 \mathrm{~K}$, the equivalent space sink temperatures have to be determined within an accuracy of a few tens of degrees.

For the space radiation case, Eq. (1) can be rewritten in terms of $T_{R}$ and $T_{S}$ as shown in Eq. (2).

Thus

$$
Q=\sigma \varepsilon F_{v} A_{s}\left(T_{R}^{4}-T_{S}^{4}\right)
$$

To calculate the equivalent space sink temperatures, $T_{s}$, in the neighborhood of planets of the Solar System, let us first consider the Sun-Earth heat radiation case as illustrated in figure 1.

Note that we want to solve for the equilibrium temperature $T_{E}$ at which the energy inflow is exactly balanced by the energy outflow. This temperature will also be equal to $T_{s}$ for "black" body radiation. For this analysis $F_{v}$ is set to unity.

Representing the Sun as a heat source at the center of a sphere whose radius is equal to mean distance between the Earth and Sun, $d$, the figure shows that about 1370 Watts fall on each square meter that is perpendicular to the radiating energy.

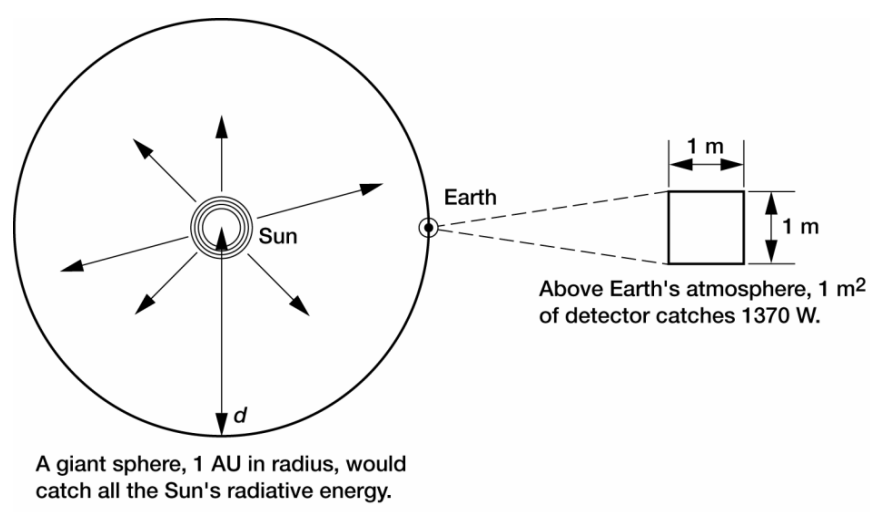

Figure 1: Sun-to-Earth thermal radiation.

The value, $1370 \mathrm{~W} / \mathrm{m}^{2}$, is referred to as the Solar Constant at $1 \mathrm{AU}$ (Astronomical Unit $=d=1.496 \times 10^{11} \mathrm{~m}$ ).

The value of the Solar Constant, $S$, can be determined by dividing the Luminosity, $L$, of the Sun, obtained in Eq. (10), by the area of the sphere with radius $=1 \mathrm{AU}$.

Expressing the above in equation form, we have

$$
S=L /\left(4 \pi d^{2}\right)
$$

Substituting for the variables: $L=3.86 \times 10^{26}$ Watts $\left(=5.23 \times 10^{23} \mathrm{HP}\right)$ and

$$
\begin{array}{ll}
d & 1.496 \times 10^{11} \mathrm{~m} \text {, with } \pi=3.14159 \\
S & 3.86 \times 10^{26} \mathrm{Watts} /\left(4 \times 3.14159 \times\left(1.496 \times 10^{11} \mathrm{~m}\right)^{2}\right) \\
& \left(\text { or } 1372.5 \mathrm{~W} / \mathrm{m}^{2}\right)
\end{array}
$$

\section{ABSORPTION, REFLECTION, AND TRANSMISSION} OF RADIATION

When electromagnetic radiation impinges on a body, it is partially absorbed, partially reflected, and partially transmitted. The relation between the absorbed, reflected, and transmitted energy can be expressed as

$$
\alpha+\rho+\tau=1
$$

where

$\alpha$ absorptivity, i.e., the fraction of the incident radiation absorbed by the body

$\rho$ reflectivity, i.e., the fraction of the incident radiation reflected from the surface of the body

$\tau$ transmissivity, i.e., the fraction of incident radiation transmitted through the body

For opaque bodies like the planets, of course, transmissivity, $\tau=0$. Equation (14) then can be expressed as

$$
\alpha+\rho=1
$$

The reflectivity of planets is also referred to as the albedo, denoted by $\mathrm{A}$. 
Thus the absorptivity can be expressed as

$$
\alpha=1-\mathrm{A}
$$

\section{THERMAL EQUILIBRIUM FOR PLANETS WITHOUT ATMOSPHERES AND SPACE SATELLITES}

\section{PLANETS}

To proceed with calculation of a radiative thermal equilibrium temperature, or equivalent space sink temperature, $T_{s}$, we define the term an energy flux or incident energy per second per unit area term $f$, where

$$
f=\text { Energy (in Watts)/Area (in } \mathrm{m}^{2} \text { ) }
$$

For thermal equilibrium

$$
f_{\text {emitted }} \times(\text { Radiating Area })=f_{\text {absorbed }} \times(\text { Absorbing Area })
$$

where from figure 1

$$
f_{\text {emitted }}=\sigma \varepsilon T_{E}^{4} \text { and } f_{\text {absorbed }}=(1-\mathrm{A}) \mathrm{L} /\left(4 \pi d^{2}\right)
$$

Since the Earth rotates about its axis once every 24 hours it is considered to be a rapidly rotating planet. This means that, on average, its entire surface can be considered to be approximately at the same temperature. Hence the total surface energy (or heat) emitted will be

$f_{\text {emitted }} \times 4 \pi R^{2}$, where $R$ is the Earth's radius

$(=6378 \mathrm{~km})$

The total heat from the Sun intercepted by the Earth is the projected Earth area on the imaginary sphere with radius $=1 \mathrm{AU}$. This area is $\pi R^{2}$. Thus the total energy absorbed will be $f_{\text {absorbed }} \times \pi R^{2}$

Substituting the expressions from Eq. (17) results in

$$
\sigma \varepsilon T_{E}^{4} \times 4 \pi R^{2}=(1-\mathrm{A}) L \times \pi R^{2} /\left(4 \pi d^{2}\right)
$$

Solving Eq. (19) for $T_{E}$ we obtain

$$
T_{E}=\sqrt[4]{(1-A) \times L / 16 \pi \sigma \varepsilon d^{2}}
$$

Substituting the numerical values for $L, d$, and $\sigma$ and simplifying, we get

$$
T_{E}=279 \times \sqrt[4]{(1-A) / \varepsilon d^{2}}
$$

where $T_{E}$ is in degrees $\mathrm{K}$
In Eq. (21) the term $d$ is expressed in $A U$, and $A U=1$ for Earth.

Solving Eq. (21) for $T_{E}$ with $\varepsilon=1$, we obtain a relatively cold temperature of $250.5 \mathrm{~K}$ for the Earth surface. However, it needs to be noted that Eq. (21) was derived for rapidly rotating planets, like Earth and Mars and atmospheric effects were not taken into account. This will be done after an examination of the thermal energy balance for slowly rotating planets.

For slowly rotating "planets" like Mercury and the Moon, one must take into account that these bodies receive energy over their projected (disk) areas and emit energy not over their full spherical surface areas but only over the same projected areas. This is because the remaining surface areas are too cold to radiate appreciable amounts of energy back into space. For these bodies the thermal equilibrium is established when

$$
\sigma \varepsilon T_{E}^{4} \times \pi R^{2}=(1-A) L \times \pi R^{2} /\left(4 \pi d^{2}\right)
$$

and

$$
\begin{gathered}
T_{E}=\sqrt[4]{(1-A) \times L / 4 \pi \sigma \varepsilon d^{2}} \\
T_{E}=394 \times \sqrt[4]{(1-A) / \varepsilon d^{2}}
\end{gathered}
$$

where $T_{E}$ is in degrees $\mathrm{K}$ and as before the Sun-Earth distance, $d$, is expressed in AU.

Applying Eq. (23) to Earth's moon, for which $d=1 \mathrm{AU}$, and $A=0.07$, we get

$$
T_{E}=394 \times \sqrt[4]{(1-0.07) / 1^{2}}=387 \mathrm{~K}
$$

The above result represents the maximum temperature at the lunar equator at noon. In contrast to the above "high" lunar temperature value, the dark side the temperature, during lunar midnight to early morning, is a frigid $70 \mathrm{~K}$, or less than $-200{ }^{\circ} \mathrm{C}$. This "low" lunar temperature results from loss of previously stored heat when the presently unlit side was fully illuminated by the

Sun half a lunar cycle earlier. When the dark side is facing the Earth at "new moon" infra-red radiation from Earth will also provide heat to the moon to keep temperatures from falling much below $\sim 70 \mathrm{~K}$.

\section{FLAT PLATE RADIATOR SURFACES}

To determine equilibrium space sink temperatures for flat plate radiators the analysis needs to take into account the solar illumination angle $\theta_{S}$, which is the angle at which the flat panel intercepts the solar flux, in addition to the ratio of solar absorptivity-to-infra red emissivity, $\alpha / \varepsilon$, of the radiating surface. 
The equilibrium temperature, $T_{E}$, for this case can then be expressed as

$$
T_{E}=\sqrt[4]{(\alpha / \varepsilon) \times L \times \sin \left(\theta_{S}\right) /\left(F_{V} \times 4 \times \pi \times \sigma \times d^{2}\right)}
$$

Equation (24) can be applied to determine the equilibrium sink temperatures experienced by a flat panel spacecraft surface traveling from the Heliopause toward the Sun. This was the procedure followed to design radiators for deep space Stirling power systems (Juhasz et al., 1999). Later the sink temperature calculation was incorporated into a dedicated code, referred to as TSCALC (Juhasz, 2001).

On its trajectory it crosses the orbits of the planets all the way into the Sun's corona. The input parameters for the calculation are: $\alpha / \varepsilon=0.6 ; \theta_{s}=25^{\circ} ; F_{v}=1 ; L=3.86 \times 10^{26}$ Watts; and $d$ is expressed in units of AU.

Table 1 shows the calculation results obtained by using a simple computational code based on Eq. (24) written by the author. In the column 1 to 4 output headings $\theta_{s}$ is represented by ILUMANG, $F_{v}$ by FV, $\varepsilon$ by EPS, and $\alpha / \varepsilon$ by $A E$. The last four columns show the orbital distances from the Sun in $\mathrm{AU}$, the solar heat flux in $\mathrm{W} / \mathrm{m}^{2}$, the sink temperature, $T_{S}$, and the reference orbit name.

Regarding the specific information presented in table 1 , several clarifications are in order. First, the reader is reminded that the temperatures shown in column 6 refer not to the temperatures of the individual planetary surfaces, but to the temperatures of spacecraft radiator surfaces being exposed to intercepted solar heat flux and infra-red re-radiation conditions as given in columns 1 to 3 , at distances from the solar heat source expressed in $\mathrm{AU}$. Second, although the illumination angle is given as 25 degrees absolute (i.e. $\pm 25^{\circ}$ ), the heat flux value, $\mathrm{Q} / \mathrm{A}$, given in column 5 is referenced to a $90^{\circ}$ insolation angle, implying perpendicular illumination. Hence the value, in $\mathrm{W} / \mathrm{m}^{2}$, is identical to the solar constant for the various orbital distances given in column 4 with the heading "AU". Finally, for the last entry, identified in column 6 as 'Photosphere', the "black body" $\alpha / \varepsilon$ ratio was used and hence 1.00 is the value entered under column heading "AE". Also the insolation angle was set at 90 degrees and the input $A U$ value represented the solar radius. The result for surface temperature, namely $5779 \mathrm{~K}$, is in excellent agreement with values published in the pertinent literature and appears to confirm the validity of the calculation technique, even for this limiting condition. The reader may should also note, that the next to last entry identified in column 6 as "Corona" shows the thermal conditions expected to be encountered on a future "Solar Peri-Helion" mission being planned by JPL.

\section{EFFECT OF PLANETARY ATMOSPHERES}

As proposed by McFarland et al., the effect of a planetary atmosphere can be introduced by considering a simple model as illustrated in figure 2. This model treats the planetary atmosphere, if one exists, as an additional radiation absorbing and radiation emitting body which needs to be included in the thermal equilibrium calculations.

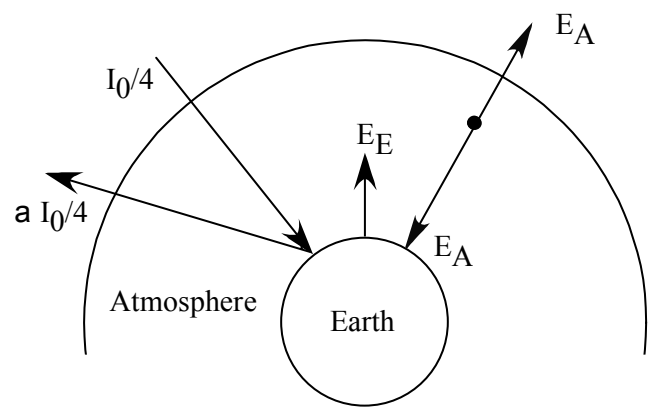

Figure 2: Simple thermal model of the Earth-atmosphere system.

Table 1: Conditions for spacecraft approaching the sun.

\begin{tabular}{cccrrrc}
$\begin{array}{c}\text { ILUMANG } \\
\text { (degree) }\end{array}$ & $\mathrm{FV}$ & $\mathrm{AE}$ & \multicolumn{1}{c}{$\mathrm{AU}$} & \multicolumn{1}{c}{$\begin{array}{c}\mathrm{Q} / \mathrm{A}\left(\mathrm{W} / \mathrm{m}^{2}\right) \\
\left(90^{\circ}\right)\end{array}$} & $\mathrm{TS}(\mathrm{K})$ & Orbit \\
25.00 & 1.0 & 0.60 & 220.0000 & 0.03 & 18.9 & Heliopause \\
25.00 & 1.0 & 0.60 & 39.4380 & 0.88 & 44.6 & Pluto \\
25.00 & 1.0 & 0.60 & 30.0578 & 1.52 & 51.1 & Neptune \\
25.00 & 1.0 & 0.60 & 19.1820 & 3.73 & 63.9 & Uranus \\
25.00 & 1.0 & 0.60 & 9.5388 & 15.08 & 90.6 & Saturn \\
25.00 & 1.0 & 0.60 & 5.2028 & 50.70 & 122.7 & Jupiter \\
25.00 & 1.0 & 0.60 & 3.0000 & 152.50 & 161.6 & Asteroids \\
25.00 & 1.0 & 0.60 & 1.5237 & 591.18 & 226.8 & Mars \\
25.00 & 1.0 & 0.60 & 1.0000 & 1372.51 & 279.9 & Earth \\
25.00 & 1.0 & 0.60 & 0.7233 & 2623.26 & 329.1 & Venus \\
25.00 & 1.0 & 0.60 & 0.3870 & 9164.15 & 450.0 & Mercury \\
25.00 & 1.0 & 0.60 & 0.0200 & 3431265.02 & 1979.3 & Corona \\
90.00 & 1.0 & 1.00 & 0.00466 & 63230822.73 & 5779.0 & Photosphere
\end{tabular}


Based on the model shown in figure 2, assuming that the Earth receives a heat flux of $\left(I_{0} / 4\right)=350 \mathrm{~W} / \mathrm{m}^{2}$ from the Sun of which $\left(I_{0} / 4\right) / \alpha$ is reflected back into space. The reader should note, that in the notation used in figure 2 the symbol $\alpha$ is used to denote the planetary "Albedo" and not the "absorptivity" as defined previously. Hence the net energy flux received by the surface is $\left(I_{0} / 4\right) \times(1-\alpha)$. Earth also radiates an amount of energy, $E_{E}$ entirely in the far infra-red part of the EM spectrum back into space, of which the atmosphere absorbs a fraction, $\beta$. But the atmosphere, considered to be also a radiating blackbody, also receives a net energy flux of $\left(I_{0} / 4\right) \times(1-\alpha)$, and reradiates an amount $E_{A}=E_{E}(1-\beta)$ into space.

For thermal equilibrium we need to equate the total thermal energy flux (energy per unit area) for the Earth surface + atmosphere system to the total outflow energy flux, as shown in Eq. (25):

$$
2\left(I_{0} / 4\right) \times(1-\alpha)=I_{E}+I_{E}(1-\beta)=I_{E}(2-\beta)
$$

Solving Eq. (25) for $I_{E}$ the following result is obtained

$$
I_{E}=\frac{2\left(I_{0} / 4\right) \times(1-\alpha)}{(2-\beta)}
$$

\section{SPECIAL CASE FOR ATMOSPHERE OF VENUS}

Since the dense atmosphere of Venus does not permit surface radiation to escape, Eq. (25) needs to be rewritten as

$$
2\left(I_{0} / 4\right) \times(1-\alpha)=I_{E}(1-\beta)
$$

so $I_{E}$ becomes

$$
I_{E}=\frac{2\left(I_{0} / 4\right) \times(1-\alpha)}{(1-\beta)}
$$

Equations 26 and 28 were added to the previously described computational code, which was then run with various input values for albedo, $\alpha$, and atmospheric absorptivity, $\beta$. This parameter was assigned the variable name BETA in the code. The results are shown Table 2 for three sets of input values for the Earth-atmosphere system and a typical input value set for the Venusian system. The three cases for the Earth system show surface temperature TS $(\mathrm{K})$ results of 280.4, 251.7, and $286 \mathrm{~K}$ for the input values of "ALBEDO" and "BETA" as shown. The remaining input parameters identified under the various headings were discussed previously, except for the surface emissivity $\varepsilon$ (EPS) which would be needed to compute heat rejection by a space radiator having a given area and radiating surface temperature. This input parameter did not affect the planetary surface temperature results.

The fourth line of Table 2 shows typical input parameters for Venus and the resulting surface temperature of $\sim 737 \mathrm{~K}$. It should be noted that even though Venus has a high atmospheric albedo of 75 percent the atmospheric absorptivity, $\beta$, for infra-red radiation from the surface is near 99 percent. This is due to the 96 percent $\mathrm{CO}_{2}$ content of the atmosphere and leads to the high surface temperature.

\section{CONCLUDING REMARKS}

A detailed derivation of the constitutive equations and relationships that describe radiant energy exchange in the Solar System has been completed and used as the basis for developing a computational code. The code incorporates determination of radiator surface temperatures at arbitrary distances from the Sun as a function of key radiating surface properties relating to absorption and emission of thermal radiation energy.

The code was enhanced by addition of a simple model to estimate surface temperatures of planets with atmospheres of varying density and opacity to emission of infrared radiation. Computed results of surface temperatures for Earth and Venus are in good agreement with values respectively obtained by terrestrial measurements or planetary probe telemetry. At present the code is used to determine equilibrium space sink temperatures needed to design space power system radiators for missions within the solar system, with computational results validated from the sun's photosphere and corona to the heliopause.

For future interstellar missions the TSCALC code can be used to determine the ecosphere dimensions for stars of interest by providing their luminosities, in lieu of the solar luminosity, as input.

\section{Table 2: Planetary atmosphere effect on surface temperature.}

$\begin{array}{ccccccccc}\begin{array}{c}\text { ILUMANG } \\ \text { (degree) }\end{array} & \text { FV } & \text { EPS } & \text { Albedo } & \begin{array}{c}\text { Beta } \\ \text { (atmospheric } \\ \text { absorptivity) }\end{array} & \text { AE } & \text { AU } & \text { TS (K) } & \text { Planet } \\ 90.0 & 4.0 & 0.80 & 0.00 & 0.00 & 1.00 & 1.000 & 280.4 & \text { Earth } \\ 90.0 & 4.0 & 0.80 & 0.35 & 0.00 & 1.00 & 1.000 & 251.7 & \text { Earth } \\ 90.0 & 4.0 & 0.80 & 0.35 & 0.80 & 1.00 & 1.000 & 286.0 & \text { Earth } \\ 90.0 & 4.0 & 0.80 & 0.75 & 0.99 & 1.00 & 0.723 & 737.1 & \text { Venus }\end{array}$




\section{REFERENCES}

Goldman, D.T.; and Singer, S.F.: Studies of a Minimum Orbital Unmanned Satellite of the Earth (MOUSE). Part III: Radiation Equilibrium and Temperature, Astronaut. Acta, vol. 3, 1957, pp. 110-129.

Gordon, Gary D.: Spacecraft Technology. Part II: Chapter 7-Thermal Control. Comsat Laboratories, March 1982, pp. 7-1 to 7-44.

Juhasz, Albert J.; Tew, Roy C.; and Thieme, Lanny G.: Design and Analysis Code for Heat Pipe Radiators of Stirling Power Systems Applicable to Deep Space Probes. Presented at the 11th International Heat Pipe Conference, (Tokyo, Japan), Sept. 1999.

Juhasz, Albert J.: An Analysis and Procedure for Determining Space Environmental Sink Temperatures with Selected Computational Results, NASA/ TM-2001-210063, January.
McFarland, Hunt, and Campbell "Energy, Physics and the Environment," Chapters 7, 12, 13, 14. Custom Publishing, 2001

Rittenhouse, John B.; and Singletary, John B.: Space Materials Handbook: Supplement 2 to the Second Edition Space Materials Experience. Lockheed Tech. Report AFML-TR-64-40, Supp. 2, 1968.

\section{CONTACT INFORMATION}

Albert J. Juhasz, Phone: 216-433-6134 


\begin{tabular}{|c|c|c|}
\hline \multicolumn{2}{|c|}{ REPORT DOCUMENTATION PAGE } & $\begin{array}{l}\text { Form Approved } \\
\text { OMB No. 0704-0188 }\end{array}$ \\
\hline \multicolumn{3}{|c|}{$\begin{array}{l}\text { Public reporting burden for this collection of information is estimated to average } 1 \text { hour per response, including the time for reviewing instructions, searching existing data sources } \\
\text { gathering and maintaining the data needed, and completing and reviewing the collection of information. Send comments regarding this burden estimate or any other aspect of thi } \\
\text { collection of information, including suggestions for reducing this burden, to Washington Headquarters Services, Directorate for Information Operations and Reports, } 1215 \text { Jefferson } \\
\text { Davis Highway, Suite 1204, Arlington, VA 22202-4302, and to the Office of Management and Budget, Paperwork Reduction Project (0704-0188), Washington, DC 20503. }\end{array}$} \\
\hline 1. AGENCY USE ONLY (Leave blank) & \begin{tabular}{|c|c|} 
2. REPORT DATE & 3. \\
July 2004 &
\end{tabular} & $\begin{array}{l}\text { D DATES COVERED } \\
\text { echnical Memorandum }\end{array}$ \\
\hline \multicolumn{2}{|c|}{$\begin{array}{l}\text { 4. TITLE AND SUBTITLE } \\
\text { Radiation in Space and Its Control of Equilibrium Temperatures } \\
\text { in the Solar System }\end{array}$} & \multirow{2}{*}{$\begin{array}{l}\text { 5. FUNDING NUMBERS } \\
\text { WBS-22-319-30-C2 }\end{array}$} \\
\hline \multicolumn{2}{|l|}{$\begin{array}{l}\text { 6. } \text { AUTHOR(S) } \\
\text { Albert J. Juhasz }\end{array}$} & \\
\hline $\begin{array}{l}\text { 9. SPONSORING/MONITORING AGE } \\
\text { National Aeronautics and } \mathrm{S}_{\mathrm{I}} \\
\text { Washington, DC 20546-00 }\end{array}$ & $\begin{array}{l}\text { NAME(S) AND ADDRESS(ES) } \\
\text { Administration }\end{array}$ & $\begin{array}{l}\text { 10. SPONSORING/MONITORING } \\
\text { AGENCY REPORT NUMBER } \\
\text { NASA TM-2004-213191 } \\
\text { 2004-01-2518 }\end{array}$ \\
\hline
\end{tabular}

Prepared for the 34th International Conference on Environmental Systems (ICES) cosponsored by the SAE, AIAA, AIChE, ASME, and the International ICES Committee, Colorado Springs, Colorado, July 19-22, 2004. Responsible person, Albert J. Juhasz, organization code 5430, 216-433-6134.

12a. DISTRIBUTION/AVAILABILITY STATEMENT

12b. DISTRIBUTION CODE

Unclassified - Unlimited

Subject Category: 88

Distribution: Nonstandard

Available electronically at http://gltrs.grc.nasa.gov

This publication is available from the NASA Center for AeroSpace Information, 301-621-0390.

13. ABSTRACT (Maximum 200 words)

The problem of determining equilibrium temperatures for reradiating surfaces in space vacuum was analyzed and the resulting mathematical relationships were incorporated in a code to determine space sink temperatures in the solar system. A brief treatment of planetary atmospheres is also included. Temperature values obtained with the code are in good agreement with available spacecraft telemetry and meteorological measurements for Venus and Earth. The code has been used in the design of space power system radiators for future interplanetary missions.

\begin{tabular}{|c|c|c|c|}
\hline \multicolumn{3}{|l|}{ 14. SUBJECT TERMS } & $\begin{array}{c}\text { 15. NUMBER OF PAGES } \\
13\end{array}$ \\
\hline NSN 7540-01-280-5500 & & & $\begin{array}{l}\text { andard Form } 298 \text { (Rev. 2-89) } \\
\text { scribed by ANSI Std. Z39-18 } \\
3-102\end{array}$ \\
\hline
\end{tabular}



